\title{
LA CONSTITUCIÓN ANTE LOS AVANCES CIENTÍFICOS Y TECNOLÓGICOS: BREVES REFLEXIONES AL HILO DE LOS RECIENTES DESARROLLOS EN MATERIA GENÉTICA Y EN TECNOLOGÍAS DE LA INFORMACIÓN Y LA COMUNICACIÓN
}

POR

\author{
POR FRANCISCO JAVIER DÍAZ REVORIO \\ Profesor Titular de Derecho Constitucional \\ Universidad de Castilla-La Mancha (Toledo)
}

\section{PLANTEAMIENTO}

En las siguientes páginas intentaré exponer, de forma necesariamente sintética y desde la perspectiva jurídico-constitucional, algunas ideas sobre el significado, el alcance y la interpretación que es necesario dar en la actualidad al sistema de valores y derechos recogidos en la Norma fundamental ante los principales avances científicos y tecnológicos de nuestros días, eligiendo en particular lo que considero son los dos aspectos más representativos de estos avances, como el desarrollo de la Genética y el alcanzado por las llamadas «Tecnologías de la Información y la Comunicación» (TIC) ${ }^{1}$.

${ }^{1}$ El presente trabajo es un breve resumen de algunas partes de una investigación más amplia y desarrollada sobre la misma materia. 
La actualidad e interés de las cuestiones que se van a abordar me parecen evidentes. Contando sólo las escasas tres décadas transcurridas desde la aprobación de la Constitución española, los avances científicos y tecnológicos, y en particular los vinculados a la Genética, por un lado, y a Internet, por otro, han sido espectaculares y enormemente sorprendentes. Incluso en un período de tiempo más breve, como puede ser lo que va transcurrido desde el inicio de la última década del siglo XX — lo que podríamos considerar el «cambio de siglo»- , pueden apreciarse significativos avances: el desciframiento del genoma humano, la clonación de mamíferos y la posibilidad de llevarla a cabo con seres humanos, la multiplicación de las posibilidades de manipulaciones genéticas y selección de embriones, la generalización del uso de las nuevas tecnologías como parte de un proceso en el que todas ellas tienden a la convergencia; y la omnipresencia de Internet, así como la multiplicación de las posibilidades comunicativas de este medio (mensajería instantánea, telefonía universal y casi gratuita, plena interactividad en la creación y emisión de contenidos), la creación de auténticos «espacios virtuales» en la red, y un largo etcétera de nuevas opciones, nos muestran un panorama no imaginado hasta hace muy poco tiempo, $y$ abren unas increíbles posibilidades de futuro, acaso en la línea de lo imaginado por Orwell, Huxley o Bradbury, o tal vez —en definitiva eso es algo que está en nuestras manos- mucho mejor.

Con todo, es importante destacar que el enfoque y la metodología de estas reflexiones son los propios del Derecho Constitucional, único ámbito que el autor de estas líneas se siente capacitado para abordar - $\mathrm{O}$ al menos intentarlo-, aunque necesariamente este empeño se quedará en el apunte de unos trazos bastantes generales. Obviamente los avances científicos y tecnológicos que se van a considerar constituyen fenómenos extrajurídicos, y por tanto el riesgo de que el trabajo vire a terrenos ajenos al ámbito del Derecho es evidente. Por ello se ha tratado en todo momento de no ignorar que el objeto de análisis no son los desarrollos científicos y tecnológicos, sino sus implicaciones para los derechos constitucionales.

Por lo demás, no basta con un enfoque jurídico del problema, sino que es necesaria una perspectiva constitucional. Lo que principalmente interesa a esta investigación no son los desarrollos en materia genética o los relativos a las nuevas tecnologías, ni siquiera sus implicaciones jurídicas, sino el proceso de adaptación y desarrollo de los derechos constitucionales para dar respuesta a los retos planteados por dichos desarrollos. Desde esta perspectiva, y aunque suele ser casi un tópico en toda investigación que se precie el hecho de señalar el carácter más o menos novedoso de la misma, en este caso basta comprobar la bibliografía específica sobre Genética o Internet en España para comprobar que, a 
pesar del tratamiento jurídico ya significativo de ambas cuestiones, son todavía escasos los trabajos llevados a cabo por constitucionalistas, o los que han abordado las cuestiones desde la perspectiva jurídico-constitucional.

No soy capaz de determinar con exactitud a qué puede deberse esta aparente "despreocupación» de nuestra disciplina por estas cuestiones (con la notable excepción del derecho a la protección de datos personales y los problemas próximos al mismo, que ya ha sido objeto de un tratamiento relativamente amplio). Sin descartar que el rápido avance de la Ciencia y la Tecnología nos haya sorprendido preocupados por otros problemas, que acaso contemplamos como más próximos o acuciantes, creo que quizás subyace, en el fondo de esta situación, la idea de que se trata de problemas más o menos ajenos al Derecho Constitucional, o cuyas implicaciones constitucionales son escasas o poco perceptibles. Seguramente la causa de esta sensación esté en el hecho de que nuestra Norma fundamental —en sentido parecido a la mayoría de las Constituciones de nuestro entorno- no contiene prácticamente ningún precepto que se dedique de manera específica a estas cuestiones, acaso con la excepción del artículo 18.4. Ello ubica la casi totalidad de la investigación en el ámbito de lo que podríamos denominar «Derecho Constitucional no escrito», y obliga a buscar las fuentes relevantes en la escasa jurisprudencia constitucional, las sentencias del Tribunal Europeo de Derechos Humanos, y algunas declaraciones y tratados internacionales que sí abordan específicamente los problemas de la Genética y de las Nuevas Tecnologías, aparte de la bibliografía procedente de las más diversas disciplinas. Hay, además, una tendencia muy extendida en el Derecho Constitucional, según la cual habría que retornar a la idea de la Constitución como un mero marco o límite negativo frente a la acción del legislador, de manera que, en todo lo que no esté expresamente previsto en la Norma fundamental, hay que abandonar cualquier pretensión de hallar una respuesta constitucional, sosteniendo simplemente la plena libertad de regulación del legislador.

Sin embargo, desde mi perspectiva hay que recalcar la consideración de que estos problemas plantean una innegable dimensión constitucional. Si bien es cierto que la Norma suprema no contiene apenas previsiones expresas, no lo es menos que incluye los valores y principios fundamentales que resultan ineludiblemente afectados por los avances a los que nos venimos refiriendo. De este modo, la dignidad, la libertad, la igualdad, la vida humana, aparte de derechos más concretos como la libertad de expresión, la libertad científica o la intimidad, entre tantos otros, no pueden ser ajenos a estos desarrollos. No creo que pueda sostenerse con rigor que la realización de intervenciones o manipulaciones genéticas que se realizan en la mayor parte de las ocasiones con embriones humanos, o la misma clonación humana, son totalmente ajenas a la 
idea de dignidad de la persona o a la protección de la vida humana; o que la voluntad de un ser humano de tener descendencia está absolutamente desvinculada del libre desarrollo de la personalidad, o que la posibilidad técnica de captar y reproducir la imagen de una persona en cualquier lugar de la superficie de la Tierra, de modo que pueda ser visualizada después por 1.100 millones de usuarios potenciales de Internet, es ajena a la preservación de la intimidad y la vida privada o, más en general, que la red no plantea cuestiones respecto al ejercicio de las libertades de expresión e información y de prácticamente todos los derechos fundamentales.

En todo caso, soy consciente de las dificultades de abordar con cierto rigor las dimensiones constitucionales de una multiplicidad de fenómenos aparentemente tan variada y heterogénea, como son los que aquí he agrupado con la etiqueta común de «recientes avances científicos y tecnológicos». No obstante, me parece que todos ellos plantean algunos problemas comunes, como son los referidos a la necesidad de adaptar la Constitución - y en particular el catálogo de derechos fundamentales - a los retos planteados por los cambios en la sociedad, y más en particular por los desarrollos de la Ciencia, últimamente tan sorprendentes y vertiginosos que nos hacen cuestionarnos si nuestra Norma fundamental contiene los valores y principios que puedan darles respuesta. Ahora bien, un examen completo y particularizado de las implicaciones de cada uno de los avances y desarrollos que contemplamos en nuestros días, excedería el objeto posible y razonable de este breve análisis. Por ello, y sin perjuicio de tener en cuenta los elementos definidores del actual mundo globalizado como "contexto" del estudio, se ha hecho necesaria una delimitación más precisa, optando por seleccionar los que se consideran factores más representativos de los actuales avances científicos y tecnológicos: la Genética e Internet ${ }^{2}$.

${ }^{2}$ Claro está que aun así el objeto de análisis conserva una acusada amplitud, que acaso hubiera aconsejado la elección de uno solo de estos dos ámbitos. Desde luego, ello hubiera sido posible, pero entonces los objetivos del trabajo hubieran sido otros, y éste mismo sería diferente, de modo que no se podría haber dado respuesta a los objetivos esenciales planteados, que como se ha tratado de exponer tienen un alcance general, al centrarse en las consecuencias constitucionales, y en particular en las implicaciones para el sistema constitucional de derechos, de los sorprendentes desarrollos científicos y tecnológicos de nuestros días, y me parece que el alcance último de esas implicaciones se habría difuminado de haber centrado el análisis en una sola dimensión específica y concreta. Dado que, como ya se ha dicho, no se trata de estudiar todas las posibles implicaciones jurídicas de un fenómeno, sino de advertir las profundas adaptaciones y transformaciones que deben acometer el sistema constitucional y los derechos en el momento actual, y ello exige una muestra suficientemente significativa de los retos a los que se han de hacer frente. Aunque ha de reconocerse que ello supone, en ocasiones, la renuncia a profundizar en el análisis de cada una de las concretas consecuencias apreciadas. En suma, interesa más un diagnóstico amplio de las con- 
Por tanto, las reflexiones que siguen tienen significativos riesgos y dificultades, como la posibilidad de abandonar el enfoque jurídico-constitucional debido al «efecto de atracción» de los fenómenos científicos y tecnológicos que han de considerarse; la escasez de trabajos previos llevados a cabo desde nuestra disciplina, y la necesidad ineludible de mantener una cierta amplitud en el objeto de estudio. Puede parecer que el anuncio de estos parámetros iniciales obedece a la necesidad de justificar lo moderado del alcance de las conclusiones. Y desde luego, no me atrevería a descartar que exista una inconsciente intención de justificar previamente el limitado alcance de los resultados. Pero creo honestamente que las dificultades que todo estudio científico entraña existen de forma especialmente acusada en un trabajo de estas características, y es preciso destacar esta circunstancia y dar a conocer los parámetros básicos en los que nos movemos. Acaso por este motivo las únicas conclusiones que razonablemente cabe esperar pueden referirse, en primer lugar, a la identificación general y particular de los valores, principios y derechos fundamentales que han de utilizarse para hacer frente a los numerosos retos que plantean a nuestra disciplina los avances científicos y tecnológicos; en segundo lugar, a la determinación de las vías y los instrumentos o mecanismos que han de utilizarse para buscar las específicas respuestas constitucionales; en tercer lugar, a la especificación de las principales consecuencias constitucionales en los ámbitos específicos de la Genética e Internet, en forma de «nuevos derechos» o desarrollo de los principios constitucionales. Y en fin, puede al menos apuntarse a un panorama de la situación de nuestra disciplina, y del camino que la misma debe emprender para encontrar su sentido en el futuro inmediato. Pero no cabe esperar que desde aquí pueda trazarse ese camino o desarrollar los parámetros sobre los que construir el nuevo Derecho Constitucional, sino simplemente apuntar algunos elementos que la investigación demuestre como imprescindibles ${ }^{3}$.

secuencias que tienen los aludidos retos para el catálogo de los derechos constitucionales, que un examen profundo de algunas de ellas. Por ello se ha preferido, por ejemplo, sistematizar un posible catálogo de «nuevos derechos» en la materia, apuntando sólo sus elementos esenciales, antes que elegir alguno de ellos y estudiarlo en todas sus implicaciones y perfiles.

${ }^{3}$ Se ha dicho que «la investigación es el proceso de entrar en los callejones para ver si no tienen salida». Acaso en esta oportunidad la salida, que se vislumbra tras un tortuoso recorrido por escarpadas y peligrosas vías, es tan amplia e incierta que sólo con apuntar en la dirección correcta se pudieran dar por buenos los resultados. 


\section{LOS RETOS DEL CONSTITUCIONALISMO EN LA ERA DE LA GLOBALIZACIÓN}

No es posible, en el contexto del presente análisis, analizar en profundidad el concepto y significado último de la globalización. Ciertamente, y a pesar de que el término es objeto de uso y abuso en todos los contextos, no es tan fácil perfilar un concepto de globalización aceptado por todos, ni delimitar con precisión su contenido o elementos. Con todo, y a los efectos que ahora interesan, basta señalar que toda una serie de factores ha provocado la superación del marco estatal vigente desde hace cinco siglos para dar protagonismo a un escenario mundial en el ámbito social, económico, cultural y científico. Todo ello en un período de tiempo realmente sorprendente, lo que ha conllevado que muchos de los parámetros hasta ahora vigentes hayan sido rápidamente superados. Las dimensiones fundamentales de este nuevo marco son la económica, social y humana, científica, tecnológica, cultural y axiológica, política y constitucional.

En este ámbito, y como marco necesario para entender el objeto del análisis, cabe señalar lo que se consideran grandes retos de este siglo XXI: los fenómenos migratorios, el terrorismo integrista, los avances científicos, y el desarrollo de las nuevas tecnologías. Ante los mismos, son varios los objetivos a cumplir por nuestras sociedades y nuestros sistemas jurídico-constitucionales. Éstos serían: la integración social, la equiparación en las condiciones básicas de vida entre las diversas sociedades, la eliminación del terrorismo, la promoción de la Ciencia y de la Medicina al servicio de la mejora de sus condiciones de vida, la preservación de la dignidad humana como derecho y como valor, la protección de la vida humana, la delimitación del concepto de persona, el desarrollo de las nuevas tecnologías, la accesibilidad tendencialmente universal de las mismas, y el establecimiento de ciertos límites necesarios a su uso.

De entre todos estos objetivos, procede centrarse en los que se refieren al desarrollo de las Ciencias de la Vida y a las TIC, y en particular nos interesan las consecuencias que estos avances tienen en el Derecho Constitucional. Por ello es preciso - a sabiendas de que no es posible un intento mínimamente fundamentado o completo- ofrecer al menos un apunte sobre el significado actual de la Constitución. Prescindiendo de otros antecedentes, en el sentido moderno este concepto tiene un origen histórico relativamente concreto, en la Revolución inglesa del siglo XVII, en la francesa del siglo XVIII, y en la independencia de los Estados Unidos, prácticamente contemporánea de ésta. Desde sus orígenes, el concepto hace referencia a la limitación del poder, al sometimiento de éste a Derecho, a la separación de poderes y a los derechos humanos. A lo largo de estos siglos, el concepto se ha ido desarrollando, avanzando desde el constitucio- 
nalismo liberal al constitucionalismo social y democrático de Derecho. Paralelamente, los derechos humanos han ido creciendo y desarrollándose. Y el concepto de Constitución ha incorporado su dimensión jurídico-formal, entendiéndose como Norma suprema de un ordenamiento, pues de otro modo mal podría cumplir su función material y garantista que existe desde su origen. Sin embargo, a pesar de este importante desarrollo, los valores fundamentales del constitucionalismo, los elementos esenciales del concepto de Constitución, han permanecido intactos y han seguido vigentes hasta finales del siglo $\mathrm{XX}^{4}$.

Con todo, hay que plantearse la cuestión de si, ante el cambio cualitativo que supone la globalización, y principalmente frente a los retos antes apuntados en los terrenos científico y tecnológico, los valores del constitucionalismo siguen teniendo validez. Al respecto, hay que apuntar que el Estado, elemento que sirve de base a la Constitución y que existe como forma de organización política moderna desde el Renacimiento, comienza a verse superado como modelo de organización, y se muestra ya como un marco claramente insuficiente para hacer frente a los fenómenos de ámbito mundial en los que estamos inmersos. Lamentablemente, nuestras sociedades aún no han sido capaces de diseñar un modelo alternativo que sea acorde con el marco global, pues nuestras organizaciones internacionales de ámbito universal no pueden hoy, ni por su estructura ni por sus competencias, asumir esta función.

La Constitución sigue hoy vinculada al marco estatal, y ésta es, sin duda, una de sus carencias, a pesar de algún tímido ensayo, por lo demás aparentemente ya abandonado, de superar ese marco. Por añadidura, la mayor parte de los textos constitucionales ignoran casi por completo los trascendentales retos y objetivos que antes mencionaba, y no establecen, salvo excepciones, valores, principios o derechos específicos que permitan ofrecer una respuesta a estas circunstancias que representan tareas y problemas ya perentorios. El Derecho Constitucional se encuentra, por tanto, en una encrucijada, pues aparentemente ha quedado superado por el rápido acontecer de los hechos y por el vertiginoso desarrollo de la Ciencia y la Tecnología.

Con todo, en mi opinión los valores esenciales presentes en la Constitución (o, si se quiere hablar en términos generales, en el constitucionalismo occidental), siguen teniendo validez. Su misma generalidad y su carácter fundamentador y fundamental dentro del sistema, y sobre todo el consenso prácticamente universal aún hoy existente sobre ellos, los hace irrenunciables, de tal manera que

${ }^{4}$ Me he referido con mayor amplitud a esta cuestión en el estudio preliminar del trabajo por mí compilado Textos constitucionales históricos. El constitucionalismo europeo y americano en sus documentos, Palestra, Lima, 2004. 
constituyen el instrumental básico para hacer frente a los nuevos retos y fenómenos de los que venimos hablando. Tendríamos, por tanto, el arsenal axiológico y ético necesario, pero eso no solventa los problemas, pues aún quedarían tareas para las que no parecen preparadas nuestras constituciones actuales:

1. La superación del marco estatal y la adecuación al nuevo ámbito global, manteniendo los valores esenciales.

2. La reinterpetación de algunos valores y conceptos básicos de la Constitución. Esta tarea no corresponde quizá a la propia Constitución en sentido propio, pero sí a los poderes y órganos encargados de desarrollarla, interpretarla y aplicarla. No se trata ahora del establecimiento de principios o derechos específicos (aspecto al que me refiero a continuación), sino de que ciertos conceptos fundamentales del Derecho Constitucional, como vida, dignidad, persona, o privacidad, requieren una nueva delimitación o una adaptación a las nuevas circunstancias. La trascendencia de esta tarea es incuestionable.

3. El establecimiento de principios y derechos específicos para hacer frente y dar cobertura a situaciones hasta hace poco inimaginables, pero que hoy necesitan respuesta a nivel constitucional, como consecuencia del vertiginoso avance que en las últimas décadas han experimentado la Ciencia y la Tecnología (desarrollo que cabe pensar será aún más notable en el futuro inmediato). Desde luego, estos nuevos principios y derechos serán compatibles con los valores esenciales o fundamentales («superiores», en términos de nuestra norma fundamental) de la Constitución, como son la libertad, la igualdad, la justicia, o la dignidad de la persona. Y en buena medida serán incluso desarrollo de los mismos, pero ello no es óbice para que esa tarea sea necesaria, pues la ambigüedad y generalidad de esos valores fundamentales puede hacerlos inadecuados para resolver las muchas cuestiones que esos avances plantean.

A pesar de la importancia de la primera de estas tareas, nos centraremos aquí en las siguientes, y en particular el establecimiento de nuevos principios y derechos.

\section{LA ADAPTACIÓN DEL CATÁLOGO DE DERECHOS A LAS NUEVAS CIRCUNSTANCIAS Y A LOS AVANCES CIENTÍFICOS}

En efecto, parece evidente que las implicaciones constitucionales de los avances científicos y tecnológicos se manifiestan de forma principal y muy acusada en el ámbito de los derechos constitucionales. El catálogo de derechos debe hacer frente a los nuevos retos planteadas por los referidos desarrollos, y ello implica, en muchos casos, la determinación de la cobertura o protección que la 
Constitución dispensa a nuevas exigencias, necesidades o facultades que requieren su protección. En esta línea, y aunque la terminología es variada (pueden mencionarse expresiones como «nuevos derechos fundamentales», «derechos no escritos»" "derechos no enumerados», «derechos innominados»" ${ }^{6}$ o "derechos implícitos» ${ }^{7}$, entre otras), utilizo aquí la expresión «nuevos derechos constitucionales» en el sentido más amplio, que engloba los nuevos ámbitos de protección jurídica, en el nivel constitucional, frente a nuevas necesidades, situaciones o valores que hay que satisfacer o proteger, tanto en su dimensión subjetiva (el derecho en sentido propio) como objetiva (el valor digno de protección constitucional). Estos «nuevos derechos» pueden tener una plasmación directa en la Constitución en sentido jurídico-formal, mediante su reforma, o bien desarrollarse mediante la interpretación que del texto constitucional realizan los Tribunales, en especial a través de la jurisprudencia constitucional.

Desde sus primeras formulaciones jurídicas, los derechos han ido creciendo por estas dos vías en todos los sistemas constitucionales (e incluso en algunos textos internacionales), y de esta manera se han ido adaptando a los cambios y avances en materia social, económica, cultural o científica. En las últimas décadas, se viene hablando de «nuevas generaciones» de derechos, que han dado protección jurídica y rango constitucional, en algunos sistemas, a la necesaria protección frente a nuevas amenazas a la persona y la Humanidad, muchas veces como consecuencia del propio progreso económico, científico y tecnológico. Así,

${ }_{5}$ He utilizado ambas expresiones en trabajos anteriores. En Valores superiores e interpretación constitucional, Centro de Estudios Políticos y Constitucionales, Madrid, 1997, págs. 457 ss., preferí la expresión «nuevos derechos fundamentales», que tenía un sentido más específico y concreto, como luego indicaré. Posteriormente, en el trabajo «Tribunal Constitucional y creación de derechos "no escritos"», en E. Espín/F. J. Díaz Revorio (coords.), La Justicia constitucional en el Estado democrático, Tirant lo blanch, Valencia, 2000, la utilización de la expresión «derechos no escritos» tiene la intención de buscar un término que permita englobar, con mayor amplitud, todos los derechos no mencionados expresamente en la Constitución, pero que de algún modo encuentran reconocimiento constitucional. El mismo término había sido usado anteriormente, por ejemplo, en el excelente trabajo de M. C. Ponthoreau, La reconnoisance des droits non-ecrits par les Cours Constitutionnelles italienne et française, Economica, Paris, 1994.

${ }^{6}$ Aparentemente estas expresiones son más propias de la doctrina americana, quizá por la influencia de la IX Enmienda de la constitución americana en otras constituciones del continente. Por todos, puede verse G. Bidart campos, «Los derechos «no enumerados» en su relación con el Derecho Constitucional y el Derecho Internacional», en http://info5.juridicas.unam.mx/ libros/1/342/6.pdf, o E. Carpio Marcos, «El significado de la cláusula de los derechos no enumerados», en Cuestiones constitucionales. Revista mexicana de Derecho Constitucional, n. ${ }^{\circ}$ 3, 2000.

${ }^{7}$ Es ésta una expresión que se utiliza muchas veces en contextos similares a las dos anteriores y con un sentido parecido, aunque puede tener un matiz más específico. 
se han incorporado al elenco de derechos constitucionales (de forma expresa o mediante "creación jurisprudencial»), derechos como el medio ambiente o el habeas data, y en el ámbito europeo se ha prohibido la clonación reproductiva.

Sin embargo, el reconocimiento de estos «nuevos derechos», y de otros que van a resultar inmediatamente necesarios ante los actuales avances, no está exento de problemas y dificultades, que se agudizan cuando no hay una proclamación constitucional expresa. Entre estos problemas cabe señalar:

1. La titularidad, dado que muchas veces ésta no puede entenderse en el sentido tradicional o clásico, sino que más bien se habla de "titularidad difusa», genérica o inconcreta, en tanto en cuanto no pueden predicarse de una o varias personas concretas, sino de la sociedad o de la Humanidad en su conjunto. Piénsese, por ejemplo, en el propio derecho al medio ambiente, o en la protección del llamado "patrimonio genético». En mi criterio, en un sentido estrictamente jurídico es preferible, en estos casos, entender que hay una protección de valores y no de derechos, con independencia de la cuestión de la legitimación procesal para instar esa defensa o protección.

2. El fundamento jurídico, aspecto éste de gran trascendencia cuando el «nuevo derecho» no se ha proclamado expresamente en la Norma fundamental. En tal caso, para justificar su protección jurídica a nivel constitucional, será necesario justificar su relación de conexión o consecuencia con alguno de los preceptos constitucionales, lo que con frecuencia sucederá en relación a ciertos principios o valores generales, permitiendo dudas interpretativas y, sobre todo, provocando que sean los tribunales, y en particular el Tribunal Constitucional, quienes asuman una función que algunos considerarán exorbitante.

3. La delimitación de su contenido y límites. Es una labor en todo caso compleja por la dificultad de precisar el sentido último de derechos - y sus concretas facultades- que carecen de la tradición jurídica de otros. Por lo demás, obviamente la labor se complica aún más si estos derechos no están expresamente reconocidos en la Constitución, pues esta delimitación necesita de una previa labor de "creación" y fundamentación, como se ha dicho.

4. La garantía. Hoy es éste un problema común a todos los derechos, pero el mismo es mucho más acusado en estos «nuevos derechos», pues los factores antes apuntados (su concreta configuración, su titularidad difusa, la necesidad de fundamentación, y la dificultad para precisar su contenido) hacen mucho más compleja la articulación de su garantía. Por lo demás, en sistemas como el español, que establece diversos mecanismos de garantía según la ubicación constitucional de los derechos, la fundamentación concreta de los posibles «nuevos derechos» determinará en buena medida la garantía de los mismos. 


\section{DERECHOS CONSTITUCIONALES, CIENCIA Y TECNOLOGÍA: VALORES APLICABLES Y CONSECUENCIAS CONCRETAS (DESDE LA PERSPECTIVA DEL SISTEMA CONSTITUCIONAL ESPAÑOL)}

Establecidas las características y problemas fundamentales de los «nuevos derechos» que permiten dar cobertura constitucional a nuevas necesidades y situaciones surgidas como consecuencia de los actuales avances científicos y tecnológicos, podemos centrarnos a continuación en analizar, principalmente desde la perspectiva constitucional española, los principios y preceptos que resultan aplicables, y la interpretación que a los mismos debe darse.

\subsection{Valores y principios constitucionales que sirven de base para dar respuesta a los retos científicos y tecnológicos}

El punto de partida ineludible es la proclamación, en el artículo 1.1 de la Constitución, de la libertad, la justicia, la igualdad y el pluralismo político como valores superiores del Ordenamiento. A mi juicio, como justifiqué en otro trabajo, a ellos puede equipararse la dignidad de la persona. Pero además de estos valores superiores, la Constitución contiene un amplio catálogo de principios y valores más concretos, muchos de ellos derivados de la misma declaración de derechos, que no tiene sólo una dimensión subjetiva, sino también una vertiente objetiva o valorativa.

Este «sistema constitucional de valores» (que en otros textos más recientes, como la Constitución europea, se ha actualizado y desarrollado de forma significativa en los aspectos que nos interesan) debe ser base suficiente para incluir la protección de las nuevas necesidades y situaciones generadas por los avances científicos y tecnológicos. Quiero decir que el carácter general y amplio de los valores proclamados permite hablar de que su conjunto posee una acusada dimensión de "plenitud» que les permite hacer frente a casi cualquier situación no prevista expresamente por el Constituyente. El Derecho Constitucional se caracteriza precisamente, en buena medida, porque su interpretación permite alcanzar un notable grado de desarrollo, desde un punto de partida compuesto por unos pocos principios y valores generales. Con todo, para hallar la respuesta a estos nuevos fenómenos es necesario realizar una interpretación de estos valores y principios tendente a la consecución de ese objetivo. Una exposición desarrollada de todas las implicaciones existentes en este ámbito es aquí de todo punto imposible, así que bastará con expresarlas de la manera más sintética.

1. La vida humana es, de acuerdo con la jurisprudencia de nuestro Tribunal Constitucional, un valor digno de protección constitucional, derivado del artí- 
culo 15 de la Norma fundamental. Sin embargo, y dado que antes del nacimiento no hay jurídicamente "persona», en esta fase la protección del nasciturus" carece de dimensión subjetiva y pose sólo esa faceta objetiva, que obliga a los poderes públicos a su protección. Queda, no obstante, por determinar el momento exacto del origen de la vida humana, es decir, el inicio de la protección constitucional. La jurisprudencia específica sobre esta cuestión utiliza el criterio de la viabilidad para determinar la existencia o no de protección constitucional, pero a mi juicio elude la precisión de ese momento en que se inicia esa protección. No obstante, de la misma jurisprudencia, y teniendo en cuenta el conjunto de preceptos constitucionales en juego, puede deducirse una protección «gradualmente creciente» de la vida humana, desde el preembrión, que sería objeto de la protección más «tenue», al ser humano nacido, que es quien goza de la protección constitucional plena.

2. La dignidad de la persona, reconocida en el art. 10.1 de la Constitución española, es un valor aplicable directamente a la solución de buena parte de las cuestiones planteadas por los avances científicos. La dignidad parece configurarse como el límite último frente a cualquier práctica o actividad, y posee no sólo su dimensión subjetiva, sino también la vertiente objetiva que protege, como valor, a la especie humana frente a cualquier atentado o lesión que tenga por objeto aquello que específicamente es definitorio de la condición "humana». Obviamente, este valor juega un papel trascendental a la hora de valorar las manipulaciones u otras prácticas desarrolladas en el ámbito de la Genética. Por lo demás, algunos de los avances en este terreno, y otros que se vislumbran para un futuro próximo, particularmente en el ámbito de la Biotecnología, cuestionarán los perfiles hoy conocidos del concepto de "persona", y con ello harán revisar las ideas hasta ahora aceptadas sobre la titularidad de los derechos.

3. La libertad, como valor superior del ordenamiento, juega también un papel importante como fuente generadora de nuevos derechos en este ámbito. Son muchas las dimensiones relevantes de la libertad (en buena medida desarrolladas por los concretos derechos fundamentales), pero aquí tiene interés particular lo que podríamos denominar «libertad-autonomía», aspecto casi coincidente con el «libre desarrollo de la personalidad» del que habla el artículo 10.1 de la Constitución, y que puede amparar, entre otros, el llamado «derecho a la reproducción».

4. El derecho a la salud, si bien constitucionalmente recogido entre los principios rectores de la política social y económica, desempeña también un papel importante a la hora de encontrar la respuesta constitucional a ciertos avances científicos en Biología, y en particular en materia Genética, pues en muchos casos las prácticas en este terreno tienen como objetivo la protección de la salud. 
5. Las libertades de expresión e información juegan un papel de enorme trascendencia en la evaluación constitucional de las TIC, dado que estas «nuevas tecnologías» pueden resultar un instrumento fundamental, en el contexto actual, para el ejercicio de estas libertades, así como para la libertad de recibir información veraz. Desde luego, las TIC permiten descubrir nuevas dimensiones, y al tiempo apuntan nuevos problemas, en relación con estas libertades, que parecen requerir, por otro lado, límites específicos cuando se ejercen por esta vía.

6. En fin, los derechos relativos a la «vida privada» reconocidos en el artículo 18 , y en particular el honor, la intimidad y la propia imagen, requieren seguramente de una protección específica en el ámbito de las nuevas tecnologías informáticas y de Internet. Especialmente hay que tener en cuenta la protección de la juventud y de la infancia como límite a las libertades de expresión e información, cuando éstas se ejercen a través de las nuevas tecnologías, pues los menores resultan muy particularmente expuestos ante los avances en este terreno. Por lo demás, el artículo 18.4, según ha sido interpretado por el Tribunal Constitucional, protege un nuevo derecho constitucional, el denominado "habeas data» o derecho a la protección de los datos personales (que hoy encuentra reconocimiento expreso en otros textos como la Constitución europea), pero ésta es sólo una de las dimensiones del ejercicio de los derechos de privacidad que se ven amenazadas por el posible abuso de las nuevas tecnologías. En fin, la limitación del ámbito geográfico propio de la protección constitucional supone un problema adicional en el contexto de prácticas cuyo alcance es universal.

Éstos son, por tanto, los preceptos constitucionales de mayor trascendencia en el tema que nos ocupa, y todos ellos requieren de una reinterpretación a la luz de los avances actuales en materia científica y tecnológica, para tratar de encontrar, sin reformar la Norma fundamental, una respuesta frente a los numerosos interrogantes que plantean estos avances. Por lo demás, con frecuencia se producirán conflictos o colisiones entre los principios, valores y derechos en juego. Éstos deben resolverse, a mi juicio, mediante la ponderación en cada supuesto concreto, y no estableciendo una relación de jerarquía entre los valores, ni partiendo de un supuesto carácter absoluto o ilimitado de alguno de ellos.

\subsection{Los derechos constitucionales ante los dos grandes retos del siglo XXI}

Si bien no es factible en este trabajo llevar a cabo un examen completo y exhaustivo de las implicaciones de cada específico desarrollo producido recientemente en el ámbito científico o tecnológico en las páginas que siguen se inten- 
tarán destacar, desde la perspectiva constitucional, las consecuencias jurídicas de las que se han considerado manifestaciones más trascendentes del desarrollo científico y tecnológico de estos inicios del siglo XXI: los avances en Genética, y las TIC, en particular Internet. Creo que este análisis es una tarea pendiente de nuestro Derecho Constitucional, y que existen razones suficientes para tratar de unir ambas situaciones, en principio diversas, pues eso permitirá extraer, de manera más fiable, conclusiones de interés sobre el papel del Derecho Constitucional, y de los «derechos constitucionales», ante estos fenómenos.

\subsubsection{Los avances en Biomedicina y Genética}

Comenzando por los avances científicos, los principales avances en este terreno se han producido dentro del ámbito de la Biomedicina, y en particular en materia Genética, sector que se ha desarrollado en los últimos años de forma espectacularmente acelerada: las manipulaciones genéticas, la selección eugenésica, la clonación, son hoy prácticas posibles, y el desciframiento del genoma humano abre la puerta a otras aún más asombrosas. Todos estos avances se pueden enmarcar en el contexto de la Bioética Resulta difícil dar un concepto preciso de Bioética, disciplina cuya implantación se ha producido en el último cuarto del siglo XX, y cuyos mismos perfiles resultan aún difusos ${ }^{8}$.

Ante estos avances, el Derecho Constitucional debe perfilar, en primer lugar, la posición constitucional del preembrión, objeto necesario de buena parte de las prácticas en este terreno ${ }^{9}$. Al respecto, y como ya se ha apuntado, es necesario de-

${ }^{8}$ El Diccionario de la Real Academia define este término como «aplicación de la ética a las ciencias de la vida", en línea con su sentido etimológico, y en el mismo ámbito parece situarse el uso más extendido del término, si bien destacando, entre los diversos aspectos que son su objeto de estudio, los vinculados a la Medicina. Queda, por tanto, una cierta imprecisión, tanto en lo relativo a su objeto de estudio, como a la perspectiva o metodología utilizada, y en particular a su vinculación con otras ciencias, aspectos en los que la amplia bibliografía ya existente en la materia (y que no podemos reflejar aquí) no establece acuerdos cerrados.

9 Desde luego, nos encontramos de nuevo ante un concepto no exento de polémica. Pero suele considerarse que el preembrión es el embrión en la primera fase de su desarrollo, que se inicia con la concepción y llega hasta el décimo cuarto día posterior a la misma. Parece que hay argumentos científicos para sostener que en torno a esta fecha se producen circunstancias muy relevantes en el desarrollo embrionario, dado que se culmina el proceso de anidación en la pared uterina, al tiempo que se forma la cresta neural, desapareciendo la posibilidad de una división que forme gemelos monocigóticos. Aproximadamente a partir de este momento las células pierden su carácter totipotencial. Por tanto, parece que la frontera de los catorce días genera cambios importantes en el desarrollo embrionario, que pueden justificar el cambio de denominación. Ciertamente, algunas opiniones cuestionan la diferenciación entre preembrión y embrión — que in- 
tallar las consecuencias de la dignidad y de la vida en esta fase del desarrollo vital. En mi opinión, esto valores configuran una protección del preembrión por parte de los valores constitucionales, si bien la misma no puede ser absoluta, y debe ponderarse con la protección, también existente, de otros derechos o valores.

En efecto, existe también justificación constitucional para proteger otros derechos y valores, que han de compaginarse con la protección del preembrión. Así, puede hablarse de un "derecho a la reproducción», que sería consecuencia del libre desarrollo de la personalidad, y para cuyo ejercicio pueden ser necesarios algunos instrumentos científicos que lo hagan posible en ciertos supuestos. Por otro lado, la misma Constitución protege el derecho a la salud, a cuyo logro van encaminadas algunas prácticas genéticas, y la producción y creación científica.

Todo ello nos lleva a un tratamiento muy matizado de estas prácticas, desde la perspectiva constitucional. Hay, desde luego, ciertos supuestos extremos que resultan contrarios a los preceptos constitucionales (en particular, a la dignidad y/o a la vida), y que están prohibidos por los textos internacionales. Así sucede con la clonación reproductiva, las prácticas eugenésicas, o la utilización lucrativa de tejidos humanos o de ciertas manipulaciones genéticas. Igualmente deben rechazarse todas las manipulaciones genéticas que no tengan una finalidad terapéutica. De todas formas, hay que ser conscientes de lo frágil que puede ser la frontera que existe entre la finalidad terapéutica y la eugenésica.

Pero descartando estos supuestos extremos, y siempre que no se desconozcan los valores en juego, existe un amplio margen para que el legislador decida qué prácticas concretas son admisibles. Así, en el caso español, el legislador español, que muy recientemente ha aprobado una regulación específica de rango legal para la investigación biomédica, había aprobado ya previamente la utilización y donación de tejidos humanos, embriones y gametos, y las técnicas de reproducción asistida, que en muchos casos tienen clara incidencia en esta materia, pues implican la previa creación de un número determinado de preembriones. Por lo demás, la legislación en esta última materia ha sufrido varios cambios, y así, la primera ley que reguló esta cuestión, aprobada en 1988 y cuya constitucionalidad fue confirmada, en términos generales, por el Tribunal Constitucional, fue reformada significativamente en 2003. Finalmente, en el año 2006 se ha aproba-

cluso parecieron tener eco en tener eco en la tramitación parlamentaria de la ley de investigación biomédica, dado que en el Senado se aprobó una enmienda para hacer desaparecer el término (enmienda número 132, de Jordi Casas i Bedós, Grupo Parlamentario CIU, Boletín Oficial de las Cortes Generales, Senado, serie II, 3 de mayo de 2007) — pero parece cierto que los cambios que he apuntado se producen aproximadamente en esa fecha del décimo cuarto día, más allá de la discusión sobre la trascendencia de los mismos y las consecuencias que puedan extraerse sobre la consideración ética o jurídica del embrión antes de esa fecha. 
do una nueva Ley sobre Técnicas de Reproducción Asistida, que resulta más abierta y permisiva en esta materia. En todo caso hay que tener en cuenta también que, como se acaba de mencionar, ciertos tratados internacionales establecen límites y prohibiciones concretas en este ámbito. Estos tratados juegan un doble papel: la función interpretativa de los preceptos constitucionales según el artículo 10.2 de la Constitución, y la fuente directa en nuestro Ordenamiento, imponiéndose por tanto a la ley.

Por lo demás, la Biotecnología permite unir estos avances científicos con los desarrollos tecnológicos, y en particular con la Robótica, dando lugar, quizá en un futuro próximo, a la creación de seres o entes cuya misma naturaleza y posición constitucional es una interrogante, y que acaso fuercen a redefinir el concepto de persona y las consecuencias del valor de la dignidad.

\subsubsection{Las Tecnologías de la Información y la Comunicación. En particular, Internet}

Un segundo ámbito en el que se manifiesta el imparable desarrollo de los años que vivimos, y que es a su vez manifestación y causa de la globalización, sería el de las llamadas «nuevas tecnologías» o, en un sentido más preciso, $\mathrm{TIC}^{10}$. Éstas han adquirido un desarrollo impresionante, y aparentemente imparable, y se han extendido, al menos en el mundo occidental, a una mayoría de personas.

Desde la perspectiva del Derecho Constitucional, las TIC plantean muchas cuestiones y problemas. En principio, estamos ante un instrumento formidable para el ejercicio de ciertos derechos fundamentales, y en particular las libertades de expresión e información. Pero además, las TIC y las redes de comunicación constituyen un ámbito amplio que configura una nueva realidad en la que la vida de la persona, y por tanto sus derechos fundamentales, pueden ejercerse. Ello implica, desde luego, la necesidad de revisar ciertos perfiles o di-

${ }_{10}$ Sin que sea posible en este trabajo detenerse en el sentido de este concepto, cabe apuntar que suelen utilizarse las expresiones «tecnologías de la información y la comunicación», «nuevas tecnologías de la información», o simplemente «nuevas tecnologías» para referirse a un conjunto de instrumentos desarrollados en las últimas décadas para la comunicación y la transmisión de la información. En un sentido amplio, la expresión hace referencia tanto a las tecnologías de la comunicación (principalmente la radio, la televisión y la telefonía en todas sus formas), como a las tecnologías de la información, vinculadas principalmente a la informática, los ordenadores y las redes que permiten el rápido flujo de esa información, principalmente Internet. Otras veces, en cambio, se le da a esta expresión un significado centrado sólo en este último aspecto, o se alude a la digitalización de los datos como el elemento esencial de estas nuevas tecnologías. 
mensiones «clásicas» de algunos derechos, cuando los mismos se ejercen en lo que podríamos denominar «mundo virtual». Así sucede, por ejemplo, con la intimidad, que puede incluir aspectos «informáticos» propios de la «realidad virtual» de una persona, de manera que, por ejemplo, invadir o conocer ciertas informaciones o especificaciones, aun en principio no íntimas, del ordenador de una persona podría entenderse como una vulneración de su intimidad. O bien, la expansión de las nuevas tecnologías hace flaquear la frontera existente entre las libertades de expresión e información, por un lado, y el secreto de las comunicaciones, por otro (con consecuencias constitucionales de indudable interés), al existir medios, como la videoconferencia, cuya finalidad oscila entre la difusión de la información, y la comunicación privada.

Por otro lado, la importancia de las TIC como instrumento de comunicación e información nos plantea la posibilidad de exigir, como necesidad propia de nuestra sociedad, el acceso de todos a las nuevas tecnologías, lo cual, en caso de existir fundamento jurídico-constitucional para ello, podría articularse como un nuevo derecho.

En fin, cabe apuntar algunas ideas más específicamente orientadas a Internet, como red de comunicación que ejemplifica perfectamente las dimensiones y la trascendencia de las cuestiones que interesan desde la perspectiva constitucional. De manera sintética podrían apuntarse los siguientes problemas o cuestiones:

1. Internet es un impresionante instrumento de comunicación, que posibilita por tanto el ejercicio de las libertades de expresión e información. Nunca antes en la Historia de la Humanidad estos derechos han resultado tan accesibles para tantas personas, ni éstas podían soñar con semejante auditorio potencial.

2. Sin embargo, este mismo instrumento puede constituir una amenaza frente a los derechos de privacidad. Esta amenaza va más allá del derecho a la protección de datos personales, y es difícil hacerla frente con los instrumentos propios de las Constituciones y legislaciones nacionales, dada la trascendencia global de Internet.

3. La posibilidad de acceder a Internet se constituye como un derecho, para cuyo ejercicio deberían garantizarse condiciones de igualdad. Pero ésta es un hoy una situación lejana, particularmente si se contempla la situación a escala mundial. De esta forma, Internet, que constituye un instrumento fundamental para «facilitar la participación de todos en la vida política, económica, social y cultural» (lo que, en términos del artículo 9.2 de la Constitución, es una obligación de los poderes públicos), puede provocar un incremento de las desigualdades entre personas y colectivos, apareciendo nuevos grupos de excluidos de esa vida social y cultural, al menos en su dimensión «virtual». 
4. Internet y las redes de comunicación pueden también utilizarse como instrumento al servicio de otros derechos fundamentales, como la participación en los asuntos públicos, y en particular el ejercicio del derecho de sufragio, mediante lo que se ha dado en llamar "voto electrónico», que en algunos lugares se ha comenzado a implantar con carácter experimental. También es un instrumento que puede facilitar la comunicación del ciudadano con la Administración y el ejercicio de sus derechos ante ésta.

5. En fin, el desarrollo vertiginoso e imparable de las nuevas tecnologías permite imaginar un futuro en el que lo que hasta hace poco se consideraba ciencia-ficción pueda realizarse y hasta generalizarse. Las redes y comunicaciones, la informática y la realidad virtual plantean nuevas situaciones que posibilitan el desdoblamiento de la persona entre su vida física y real, y una posible y paralela vida «virtual» en la que desarrolla su personalidad y ejerce sus derechos, todo lo cual plantea, desde la perspectiva de los derechos constitucionales, retos que hoy sólo somos capaces de intuir. Para hacer frente a ellos es preciso haber establecido previamente cuáles son los valores jurídico-constitucionales que hay que utilizar, y cuál es el sentido, significado y contenido que los mismos deben tener, de manera tal que contemos con los elementos necesarios para precisar la respuesta jurídica que corresponde dar a esos retos.

\section{REFLEXIONES FINALES}

En las páginas anteriores se ha intentado poner de relieve las implicaciones constitucionales de los recientes avances científicos y tecnológicos, tomando como ejemplos más representativos y llamativos los desarrollos producidos en materia genética, y los últimos avances en el terreno de las nuevas tecnologías de la información y la comunicación. Sin embargo, hay que ser conscientes de que este tipo de análisis conducía finalmente a una reflexión mucho más amplia, que tiene que ver con el propio sentido actual de la Constitución y del Derecho Constitucional. Por eso estas reflexiones nos han conducido por un camino en cuyo destino se apreciaba la gran tarea de nuestra disciplina en la actualidad, que no es otra que la construcción de un nuevo Derecho Constitucional, acorde con la nueva Era histórica en la que sin duda estamos entrando. Obviamente, un objetivo de tal calado está lejos del alcance de un trabajo de estas características, al menos se ha intentado sugerir ciertos parámetros, principios o ideas básicas en la materia, que en definitiva pueden ayudar u ofrecer cierta utilidad para emprender esa gran tarea pendiente. 
Cabe decir como apunte final que está pendiente la elaboración de un nuevo Derecho Constitucional para el siglo de la globalización. Es una ardua tarea, que aquí obviamente ni siquiera se ha intentado — pues su mera pretensión asusta como objetivo a acometer-, pero al menos se ha buscado sugerir elementos con los que nuestro sistema constitucional (y más ampliamente, el constitucionalismo) pueda hacer frente a los avances científicos y tecnológicos ya existentes, y a los que se anuncian de inmediato. Dichos avances (que son a su vez causa, en buena medida, de la creciente globalización), parecen conducirnos a una nueva era, y suponen un reto sin precedentes para el constitucionalismo. Debemos, por tanto, iniciar la labor de construcción de un nuevo constitucionalismo. Ya se ha reiterado la insuficiencia del marco estatal, al que siempre se ha vinculado la Constitución, para hacer frente a este nuevo panorama. Además, los avances no nos plantean sólo la cuestión de qué nuevos derechos debemos reconocer, sino también la de si siguen siendo válidos los valores fundamentales que han estado vigentes durante siglos. El cambio es de tal calado que puede remover los cimientos del constitucionalismo, pero carecemos aún de las herramientas necesarias para hacerle frente; $\mathrm{o}$, al menos, contamos sólo con las herramientas que nos proporcionan los valores constitucionales. Somos conscientes de que nuestro modelo se ve superado por los acontecimientos, pero no hemos sido capaces de construir otro. Los mismos conceptos de persona, dignidad, vida, libertad, entre otros, parecen tener unos límites demasiado estrictos para hacer frente a los problemas y situaciones que ya se están planteando, y a los que se apuntan para un futuro inmediato. No obstante, el nuevo constitucionalismo, que debe superar el marco estatal y adaptarse a una realidad global, debería construirse sobre los mismos valores de limitación al poder, democracia, libertad, igualdad, dignidad y vida, interpretados con la amplitud que deriva de la necesidad de adaptar los mismos a estas nuevas realidades cuya vertiginosa implantación nos ha alcanzado por sorpresa.

\section{BREVE REFERENCIA BIBLIOGRÁFICA}

Dada la amplitud de los temas abordados en este escrito, existe abundante bibliografía sobre los mismos (aunque ciertamente, como ya se ha apuntado, no es tan numerosa la producida desde la disciplina del Derecho Constitucional). A continuación me limitaré a ofrecer algunas referencias básicas en relación a las diversas materias abordadas.

ABELLÁN, F., Selección genética de embriones. Entre la libertad reproductiva y la eugenesia, Comares, Granada, 2007. 
Alegre Martínez, M. A., La dignidad de la persona como fundamento del ordenamiento constitucional español, Universidad de León, 1996.

AleXY, R., Teoría de los derechos fundamentales, versión castellana del original "Theorie der Grundrechte», por E. Garzón Valdés, Centro de Estudios Constitucionales, Madrid, 1993.

Andorno, R., Bioética y dignidad de la persona, Tecnos, Madrid, 1998.

ASENSI SABATER, J., La época constitucional, Tirant lo blanch, Valencia, 1998.

BAllesteros, J. (ed.), Derechos humanos, Tecnos, Madrid, 1992.

BASTIDA Freijedo, F., et alii, Teoría general de los derechos fundamentales en la Constitución española de 1978, Tecnos, Madrid, 2004.

BENDA, E., "Dignidad humana y derechos de la personalidad", en E. Benda et al., Manual de Derecho Constitucional, traducción de A. López Pina, IVAPMarcial Pons, Madrid, 1996.

Blázquez Ruiz, J., Derechos humanos y Proyecto Genoma, Comares, Granada, 1999.

BÖCKENFÖRDE, E. W., Escritos sobre derechos fundamentales, Nomos Verlagsgesellschaft, Baden-Baden, 1993.

CASTELlS, M., La galaxia Internet. Reflexiones sobre Internet, empresa y sociedad, Areté, Plaza \& Janés, Barcelona, 2001.

Castells, M., La era de la información. Economía, sociedad y cultura, Alianza, Madrid, 2. ${ }^{\text {a }}$ ed., 3 vols., 2000-2001.

DaVAra RodrígueZ, M.A. (coord.), Diez años de encuentros sobre Informática y Derecho, 1996-1997, Aranzadi, 1997.

DENNINGER, E., «Racionalidad tecnológica, responsabilidad ética y Derecho postmoderno", en Doxa, n. ${ }^{\circ} 14,1993$.

DíAZ Revorio, F. J., "El valor histórico de la Constitución», estudio preliminar en F.J. Díaz Revorio (ed.), Textos constitucionales históricos, Palestra, Lima, 2004.

DíEz-Picazo Giménez, L. M., Sistema de derechos fundamentales, Civitas, Madrid, 2. ${ }^{\text {a ed., } 2005 .}$

DwOrkin, R., El dominio de la vida, versión española de Ricardo Caracciolo y Víctor Ferreres, Ariel, Barcelona, 1994.

FARIÑAS DulCE, M. J., Globalización, ciudadanía y derechos humanos, Dykinson, Madrid, 2000

FERnÁNDEZ EstebAn, M. L., Nuevas tecnologias, Internet y derechos fundamentales, McGraw Hill, Madrid, 1998.

FERNÁNDEZ ESTEBAN, M. L., "Internet y los derechos fundamentales», en Anuario Jurídico de La Rioja, n. ${ }^{\circ}$ 6-7, 2000-2001.

FERNÁNDEZ RODRÍGUEZ, J. J., «En torno a las nuevas dimensiones de la libertad 
de expresión ante el fenómeno de Internet», en Pensamiento Constitucional, Año VIII, n. ${ }^{\circ}$ 8, 2002.

FreIRE DE SÁ, M. F., «Principios y límites jurídicos de la investigación con embriones humanos», en Revista de Derecho y Genoma Humano, n. ${ }^{\circ}$ 19, 2003. Freire FalCÂO DE Oliveira, G., «Implicaciones jurídicas del conocimiento del genoma (I)», en Revista de Derecho y Genoma Humano, n. ${ }^{\circ}$ 6, 1997.

Freire Falcâo de Oliveira, G., «Implicaciones jurídicas del conocimiento del genoma (II)», en Revista de Derecho y Genoma Humano, n. ${ }^{\circ}$ 7, 1997.

FRÜHWALD, W., et alii, «La clonación humana: fundamentos biológicos y valoración ético-jurídica», en Revista de Derecho y Genoma Humano, n. ${ }^{\circ}$ 9, 1998.

Gafo, J. (ed.), Directrices éticas de la manipulación genética, Universidad Pontificia de Comillas, 1988.

García MeXía, P. (dir.), Principios de Derecho de Internet, tirant lo blanch, Valencia, 2005

GonZÁlez Pérez, J., La dignidad de la persona, Civitas, Madrid, 1986.

Gros EsPiell, H., «El patrimonio común de la humanidad y el genoma humano", en Revista de Derecho y Genoma Humano, n. ${ }^{\circ}$ 3, 1995.

Gutiérrez Gutiérrez, I., Dignidad y derechos fundamentales, Marcial Pons, 2005.

JiméNeZ Asensio, R., El constitucionalismo. Proceso de formación y fundamentos del Derecho Constitucional, Marcial Pons, Madrid, 2. ${ }^{a}$ ed., 2003.

LEJEUNE, D., Biotecnologia y futuro del hombre: la respuesta bioética, Eudema, 1992.

LLANEZA GONZÁlEZ, P., Internet y comunicaciones digitales: régimen legal de las tecnologías de la información y la comunicación, Bosch, Barcelona, 2000.

LUCAS MuRILlO DE LA CUEVA, P., Informática y protección de datos personales, Centro de Estudios Constitucionales, Madrid, 1993.

Martín Mateo, R., Bioética y Derecho, Ariel, Barcelona, 1987.

Martínez Bullé-Goyri, V. M., «Bioética y Derecho», en S. García Ramírez (coordinador), Los valores en el Derecho mexicano. Una aproximación, Instituto de Investigaciones Jurídicas, UNAM, México, 1997.

MarTínez Bullé-Goyri, V. M. «El estatuto jurídico del embrión humano», en J. González Valenzuela (coord.), Dilemas de Bioética, México, UNAM-Comisión Nacional de los Derechos Humanos-FCE, 2007.

Martínez Bullé-Goyri, V. M. La investigación con embriones humanos. Aspectos bioéticos y biojurídicos (libro en prensa).

Modugno, F., I "nuovi diritti” nella Giurisprudenza costituzionale, G. Giappichelli, Turín, 1995.

MOles y PlazA, R. J., Derecho y control en Internet: la regulabilidad de Internet, Ariel, Barcelona, 2003. 
Muñoz Machado, S., La regulación de la red. Poder y Derecho en Internet, Taurus, Madrid, 2000.

Murillo Villar, A., Bello Paredes, S. A., Estudios jurídicos sobre la sociedad de la información y nuevas tecnologías, con motivo del XX aniversario de la $\mathrm{Fa}$ cultad de Derecho de Burgos, Universidad de Burgos, 2005.

Ochoa Olascoaga, B., y Caballero Harriet, F. J., La Biología frente a la Ética y el Derecho, Universidad del País Vasco, 1988.

Perez Luño, A. E., Derechos humanos, Estado de Derecho y Constitución, Tecnos, 8. ${ }^{\mathrm{a}}$ ed., Madrid, 2003.

Perez Luño, A. E., Manual de informática y Derecho, Ariel, Barcelona, 1996.

Prieto Sanchis, L., Estudios sobre derechos fundamentales, Debate, Madrid, 1990.

PrieTO SANCHIS, L., "La limitación de los derechos fundamentales y la norma de clausura del sistema de libertades", en Derechos y libertades, n. ${ }^{\circ} 8$, año 2000.

REVENGA SÁNCHEZ, M., «Sobre (viejos) modelos de justicia constitucional y creación de (nuevos) derechos", en Revista Española de Derecho Constitucional, n. ${ }^{\circ}$ 64, 2002

Romeo Casabona, C. M., El Derecho y la Bioética ante los límites de la vida humana, CEURA, Madrid, 1994.

Romeo Casabona, C. M. (ed.), Genética Humana, Universidad de DeustoFundación BBV-Diputación Foral de Bizkaia, Bilbao, 1995.

Serrano Ruiz-Calderón, J. M., Nuevas cuestiones de Bioética, EUNSA, Pamplona, 2002.

VÁzQUEZ, R. (coord.), Bioética y derecho. Fundamentos y problemas actuales, Fonmdo de Cultura Económica, México, 2. ${ }^{a}$ ed., 1999.

Vera SANTOS, J. M., "Derechos fundamentales, Internet, y nuevas tecnologías de la información y de la comunicación», en P. García Mexía, Principios de Derecho de Internet, tirant lo blanch, Valencia, 2005.

Villagrasa AlCAide, C. (coord.), Nuevas tecnologías de la información y derechos humanos, Cedecs, Barcelona, 2003.

VV.AA., Proyecto Genoma Humano: Ética, Fundación BBV, Bilbao, 2. ${ }^{a}$ ed., 1993.

VV.AA., El Derecho ante el Proyecto Genoma Humano, Fundación BBV, Bilbao, 1.994-1.995 (4 vols.).

VV.AA., La vida humana. Origen y desarrollo, Universidad Pontificia de Comillas, Madrid, 1989.

VV.AA., Derechos humanos y nuevas tecnologias, Ararteko, San Sebastián, 2003. ZarraluQui, L., Procreación asistida y derechos fundamentales, Madrid, 1988. 


\section{Title}

The Constitution in face of scientific and technological advances: brief reflections on recent developments in Genetics and Information and Communication Technologies

\section{Resumen}

El fenómeno actual de la globalización plantea algunos grandes retos, como los fenómenos migratorios, el terrorismo integrista, los avances científicos, y el desarrollo de las nuevas tecnologías. Todos ellos tienen notables repercusiones en el ámbito constitucional, de manera que el constitucionalismo debe hacer frente a estos vertiginosos cambios, en particular los que tienen lugar en el ámbito científico y en el tecnológico. Para ello, a juicio del autor, han de mantenerse los valores propios del constitucionalismo, que se establecieron en los orígenes de la Edad contemporánea y se han desarrollado en los últimos siglos, aunque el catálogo de los derechos fundamentales debe desarrollarse e incrementarse por diversas vías para dar cabida a las nuevas necesidades.

En este trabajo se analiza esta problemática, con referencia particular a los avances producidos en materia genética y en las tecnologías de la información y la comunicación. A estos efectos se toman como referencia los valores constitucionales que han de utilizarse para dar respuesta jurídica a estos avances, como la dignidad de la persona, la vida, el derecho a la salud, la libertad de expresión y sus límites, la libertad de las comunicaciones. A continuación se analizan las principales implicaciones de los desarrollos en los citados ámbitos, abordando asuntos como la posición constitucional del preembrión, el patrimonio genético, los derechos a la integridad e identidad genética, o el derecho a la reproducción, en lo relativo a los avances genéticos; o la delimitación entre libertad de expresión y secreto de las comunicaciones, el derecho de acceso a las nuevas tecnologías, o las implicaciones de internet en el ámbito de los derechos fundamentales, en particular en los derechos de privacidad y en los derechos de participación en la vida política y social. Del análisis se deduce la entidad del impacto que estos avances tienen para el catálogo de los derechos fundamentales y para el Derecho constitucional, que sin embargo tienen los valores del constitucionalismo como único instrumento para ofrecer las respuestas a estos retos.

\section{Abstract}

Present phenomenon of globalization raises some great challenges, like migratory phenomena, integrist terrorism, scientific advances, 
and development of new technologies. All of them have remarkable repercussions on constitutional scope, so that constitutionalism must face up to these dizzy changes, in scientific and technological scopes specially. Constitutional values, settled down in the origins of Contemporary Age and developed in the last centuries, must stay, although fundamental rights catalogue must be developed and increased in several ways to offer an answer to new necessities.

This issue is discussed, with particular reference to developments in Genetics and Information and Communication Technologies. Constitutional values used to give response to these developments, as human dignity, life, the right to health, freedom of expression and its limits, freedom of communications, are the starting point. Next the main implications of the developments in the mentioned scopes are analyzed, approaching subjects like constitutional position of the preembryo, genetic patrimony, the rights to integrity and genetic identity, or the right to the reproduction, (in relation to genetic advances); or the boundary between freedom of expression and secret of communications, the right to access to new technologies, or the implications of Internet in the scope of fundamental rights, in particular in the rights of privacy and participation in political and social life. Finally it's possible to deduce the importance of the impact of these advances in fundamental rights catalogue and in Constitutional Law; nevertheless, values of constitutionalism are the only instrument that can offer answers to these challenges.

\section{Palabras clave}

Constitución, Derecho Constitucional, derechos fundamentales, constitucionalismo, dignidad de la persona, valores constitucionales, vida, libertad de expresión e información, secreto de las comunicaciones, vida privada, genoma, Genética, clonación, embrión, preembrión, reproducción, tecnologías de la información y la comunicación, nuevas tecnologías, internet

\section{Key words}

Constitution, Constitutional Law, civil rights, constitutionalism, human dignity, constitutional values, life, freedom of expression and information, secret of the communications, privacy, genome, Genetics, cloning, embryo, pre-embryo, reproduction, information and communication technologies, new technologies, Internet 